\title{
REVIEW
}

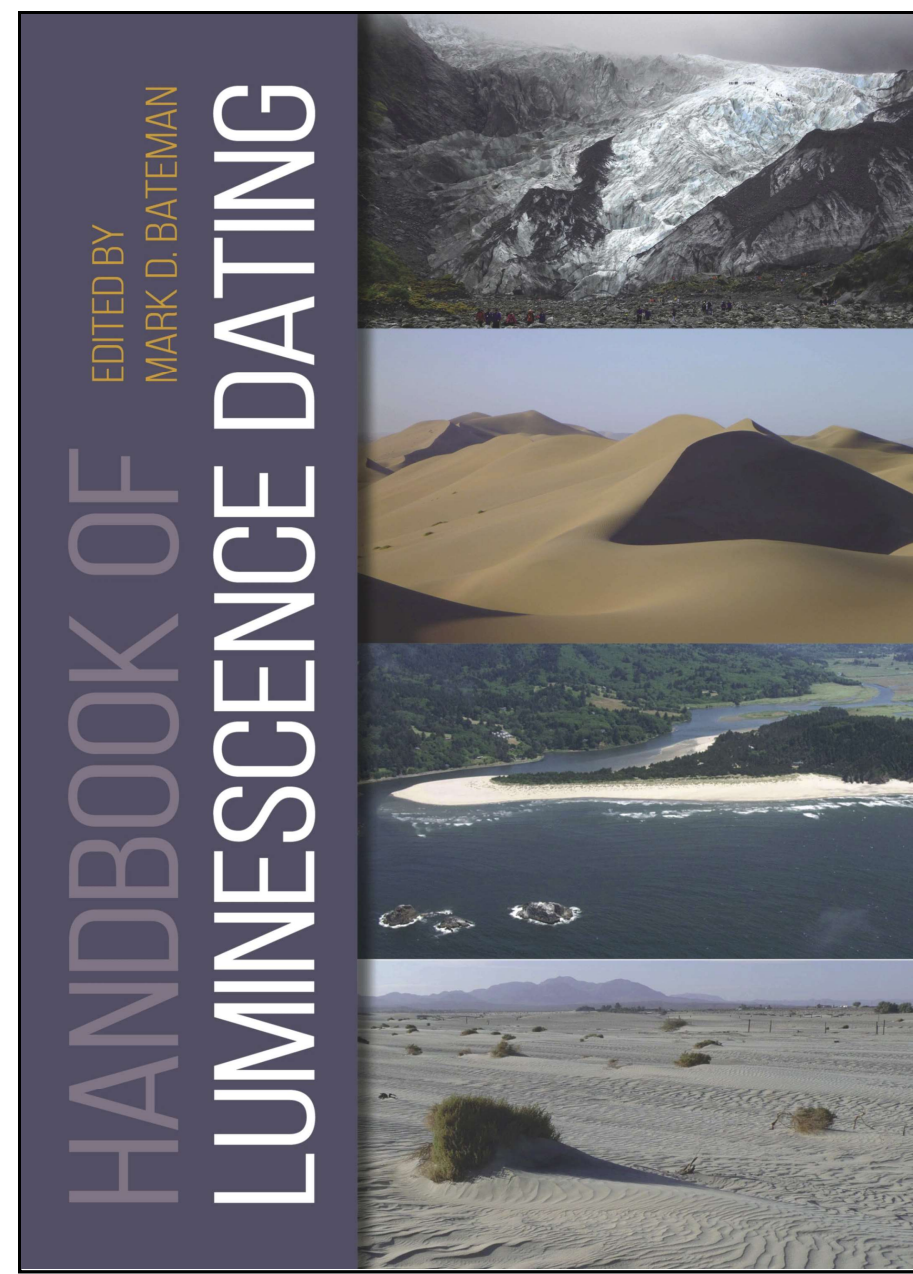

\section{Handbook of Luminescence Dating}

\section{Mark D. Bateman, editor}

Published by: Whittles Publishing, Dunbeith, Scotland.

Published: 2019; 416 p.

Purchase price: $\$ 163$ (CND; Hardback).

\author{
Reviewed by Norm Catto \\ Memorial University \\ Department of Geography \\ St. John's, Newfoundland and Labrador, A1B 3X5, Canada \\ E-mail:ncatto@mun.ca
}

Luminescence dating techniques, including optically and infrared-stimulated luminescence and thermoluminescence, have been widely applied in the past 20 years. Formerly 'undateable' Quaternary sediments and successions can now be assessed chronologically, allowing interpretation of aeolian, fluvial, glacial, coastal, mass movement, and tectonic features, in addition to archaeological materials. For Quaternarists not directly involved in the luminescence community, knowledge of the evolving techniques and understanding of the current (and previous) limitations and future possibilities is important. The volume is aimed at professional and academic Quaternary geoscientists, and graduate and senior undergraduate students, looking to engage with the background, techniques, and applications of luminescence dating.

The Handbook of Luminescence Dating contains 12 chapters written by authors based in nine countries. Reflecting the history of luminescence, particularly optical, dating, many of the authors have ties to the University of Oxford and/or Royal Holloway University London. However, the authors represent a cross-section of researcher efforts across the spectrum of luminescence studies.

The opening chapter by Mahan and Dewitt introduces the principles and history of the various forms of luminescence dating, which provide chronological data for materials ranging from approximately 780,000 a to the last 100 years. Applications outlined include medical uses, assessment of prehistoric wildland fire events, dating of archaeological ceramics, and authentication of the age of artworks. Terminological definitions and analytical techniques, often not included in professional articles written by luminescents for luminescents, are introduced for the benefit of non-specialists. Discussion of accuracy, precision, and reproducibility allow readers to understand the parameters necessary for understanding the reported chronological data.

Bateman discusses the processes from sampling to data reporting. Sampling technique is critical to the production of usable chronological data. As many samples destined for luminescence are collected by Quaternarists not directly associated with dating laboratories, understanding what, where, and how to sample is critical. This is probably the most important chapter in the volume and would be the first that I would recommend that field researchers should thoroughly digest. Bateman's recommended procedures are easily understood, and will save much future uncertainty and grief.

Clark-Baysan outlines the role of Bayesian analysis in the production of chronometric frameworks. This chapter includes discussion of Bayesian techniques in general, expand- 
ing beyond luminescence analyses, concluding with archaeological and glacial chronological case studies.

Luminescence applications in aeolian environments are discussed by Fitzsimmons, who focuses on sandy sediments. Difficulties relating to pedogenesis, partial bleaching, low dose rates, and moisture content are considered. The second half of the chapter discusses application of the techniques to investigation of dune sequences as climate archives.

Loess is probably the most commonly dated material using optically stimulated luminescence. Stevens outlines the issues involved in loess dating, with consideration of the use of loess deposits as testbeds for luminescence techniques. The importance of loess-palaeosol sequences as climate archives, and the very limited possibilities of dating pre-MIS $5 e$ deposits with other techniques, have made luminescence dating an essential element in palaeoclimate analysis in many locations in Europe, China, and elsewhere. Continued development of infraredstimulated luminescence has allowed dating of mid-Quaternary successions.

Bateman considers applications in glacial and periglacial environments. These regimes demand care in sampling technique and interpretation of results, requiring analysis of small aliquots or (ideally) single grains. Application of statistical techniques can improve accuracy. Applications in fluvial and hillslope environments are considered by Fuchs. Variations in dose rate and sunlight exposure in these environments are common, requiring careful consideration.

Cunningham et al. discuss the application of luminescence dating to coastal and marine environments. Although some researchers might initially consider coastal deposits to be unsuitable, the combination of high proportion of quartz and exposure to sunlight through reworking allow luminescence dating to be applied effectively. Greater challenges exist in attempting to date estuarine, lagoonal, deltaic, and prodelta deposits. Complications resulting from the presence of Useries nuclides are also discussed.

Rhodes and Walker discuss applications of luminescence dating to active tectonic regimes. This chapter highlights the use of Quaternary research for a practical purpose - assessing the frequency of earthquake activity. Quaternary research ideally should contribute to society as a whole, and not only provide interesting things for Quaternary researchers to do. Luminescence dating provides an important context in hazard assessment.

Bailiff discusses archaeological applications of various forms of luminescence dating. Thermoluminesecence, less emphasized in the preceding chapters, is employed in archaeological investigations, and is well-treated here. King et al. focus on the use of luminescence techniques for dating exposed rock surfaces in chapter 11 . In the final chapter, Wallinga provides insight on the potential future evolution of luminescence analysis.

Together, the twelve chapters in this volume provide a succinct summary of the techniques, applications, limitations, and future of luminescence analysis. This volume is recommended as a useful acquisition for senior undergraduate and graduate Quaternary programs. 